Paidéia, 2003, 13(26), 147-156

\title{
RESILIÊNCIA: CONCEPÇÕES, FATORES ASSOCIADOS E PROBLEMAS RELATI- VOS À CONSTRUÇÃO DO CONHECIMENTO NA ÁREA ${ }^{1}$
}

\author{
Mara Regina Santos da Silva ${ }^{2}$ \\ Fundação Universidade Federal do Rio Grande \\ Ingrid Elsen \\ Universidade Federal de Santa Catarina \\ Carl Lacharité \\ Université du Québec à Trois-Rivières
}

\begin{abstract}
Resumo: A resiliência caracteriza-se pela capacidade do ser humano responder de forma positiva às demandas da vida quotidiana, apesar das adversidades que enfrenta ao longo de seu desenvolvimento. Tratase de um conceito que comporta um potencial valioso em termos de prevenção e promoção da saúde das populações; mas, ainda permeado de incertezas e controvérsias. O objetivo deste artigo é trazer uma revisão de estudos, focalizando convergências e divergências nas concepções de resiliência de diferentes autores, além de apresentar o que tem sido analisado como fatores de risco e de proteção a ela associados, pontuando os problemas identificados na construção do conhecimento acerca deste fenômeno. O material revisado evidencia que, apesar do conhecimento já produzido, não existe, ainda, uma definição de consenso acerca de resiliência e sua operacionalização constitui-se em um desafio com que se deparam os pesquisadores, em alguma etapa de seus estudos.
\end{abstract}

Palavras-chave: resiliência, fatores de risco; fatores de proteção

\section{RESILIENCE: CONCEPTIONS, ASSOCIATED FACTORS AND RELATED PROBLEMS WITH THE CONSTRUCTION OF THIS KNOWLEDGE}

\begin{abstract}
Resilience is defined as the human capacity to positively answer to daily life demands, despite the adversities it faces during its development. It is understood as a concept that holds a great potential concerning preventing and promoting health among populations; even though, it is still embraced by uncertainties and controversies. The aim of this paper is to provide a study review, focusing on conversions and diversions of the resilience conceptions from different authors, besides presenting what has been analyzed as risk and protection factors associated to it, pointing out the problems found in the construction of the knowledge about such phenomenon. The reviewed material illustrates that despite the knowledge already produced there is not a consensus about the definition of resilience yet, and its procedure represents a great challenge for researchers along their studies.
\end{abstract}

Key-words: Resiliense, Risk factors, Protection

Nos domínios das ciências humanas e da saúde, o conceito de resiliência faz referência à capacidade do ser humano responder de forma positiva ${ }^{3}$ às situações adversas que enfrenta, mesmo quando estas comportam risco potencial para sua saúde e/ou

\footnotetext{
${ }^{1}$ Artigo recebido p/ publicação em 28/09/2003; aceito em 18/12/2003.

${ }^{2}$ Endereço para correspondência: Mara Regina Santos da Silva, Rua Frederico Carlos de Andrade, 750, Cassino, Rio Grande, RS, Cep 96208050, E-mail: mara@vetorial.net
}

seu desenvolvimento. Esta capacidade é considerada por alguns autores como uma competência individual que se constrói a partir das interações entre o sujeito, a família e o ambiente e, para outros, como

\footnotetext{
${ }^{3}$ O termo "resposta positiva” faz referência à maneira como estes seres humanos administram as adversidades que enfrentam ao longo de seu desenvolvimento, reconhecendo seu potencial de risco, mas sem perder a capacidade de mobilizar os recursos pessoais que possuem e, quando necessário, os recursos contextuais que lhes possibilitam enfrentar essa situações e não sucumbir diante delas.
} 
uma competência não apenas do sujeito, mas, também, de algumas famílias e de certas coletividades. Trata-se, portanto, de um fenômeno complexo, atrelado à interdependência entre os múltiplos contextos com os quais o sujeito interage de forma direta ou indireta e sobre o qual incide diferentes visões.

De forma geral, Walsh (1998) considera que a resiliência implica mais do que meramente sobreviver à situação adversa ou escapar de alguma privação. Representa uma contraposição à idéia de que os sujeitos que crescem em ambientes adversos estão fadados a se tornarem adultos com problemas. Para exemplificar, a autora refere que os sobreviventes de experiências catastróficas não são necessariamente pessoas resilientes; alguns deles podem centrar suas vidas em torno das experiências negativas que vivenciaram, negligenciando outras dimensões de seu viver, enquanto que as pessoas resilientes desenvolvem certas habilidades que lhes possibilitam assumir o cuidado e o compromisso com sua própria vida.

Enquanto objeto de investigação, a resiliência tem sido examinada de forma sistematizada no decorrer das últimas três décadas, a partir de trabalhos desenvolvidos com crianças vivendo em ambientes com múltiplos riscos psicossociais. Dentre esses, o estudo longitudinal coordenado por Werner (1995) que acompanhou, durante 32 anos, uma coorte de 698 crianças nascidas em 1955, na ilha de KauaiHawaii, dentre as quais aproximadamente um terço $(n=201)$ foi considerada de alto risco, pois vivia em famílias cronicamente pobres e havia experienciado estresse perinatal, instabilidade familiar, discórdia e problemas de saúde física e mental nos pais. Este estudo avaliou, entre outros aspectos, as conseqüências, a longo prazo, das condições adversas sobre o desenvolvimento físico, cognitivo e psicossocial dessas crianças, identificando que, na vida adulta, uma parte desse grupo $(n=72)$ se desenvolveu como pessoas que, sob o ponto de vista vocacional e acadêmico, foram consideradas competentes, confiantes e capazes de administrar sua vida dentro de padrões considerados normativos, apesar de terem crescido sob condições desvantajosas. A outra parte do grupo de crianças, que também viveu em condições de alto risco, manifestou sérios problemas de aprendizagem, além de registros de delinqüência e problemas de saúde mental.
O acompanhamento deste grupo, ao longo de seu desenvolvimento, mostrou que as crianças que se desenvolveram de forma normativa, apesar das adversidades, foram aquelas que puderam contar com um conjunto de fatores de proteção que incluía laços afetivos positivos dentro da família com pelo menos um cuidador (um dos pais, um irmão, avós ou pais substitutos) e haviam experienciado poucas separações prolongadas de seu cuidador primário, durante o primeiro ano de vida. Além disso, encontraram suporte emocional fora de casa, geralmente de um professor na escola, de amigos ou outra pessoa que as apoiavam, principalmente nos períodos de maior estresse.

Outro estudo longitudinal que representa um marco inicial para o desenvolvimento da pesquisa sobre resiliência foi conduzido por Michel Rutter que acompanhou, durante dez anos (de 1979 a 1989), 125 crianças cujos pais eram portadores de doença mental. A constatação de que muitos desses filhos não sucumbiram às privações e às adversidades a que estavam expostos na infância e não apresentaram qualquer tipo de doença mental ou problemas de comportamento, serviu de ponto de partida para a investigação, no sentido de compreender como elas conseguiram evitar os efeitos negativos da convivência com a doença mental e identificar o que as protegia dos perigos potenciais a que estavam expostas (Zimmerman \& Arunkumar, 1994).

Sem dúvida, resiliência é um conceito importante, com múltiplas possibilidades de aplicação, uma vez que pode contribuir para maior compreensão acerca do processo de produção de saúde que se desenrola em meio à aparente desorganização provocada, muitas vezes, pelas adversidades com as quais os seres humanos se deparam ao longo de sua existência. Principalmente em termos de desenvolvimento humano, a resiliência ajuda a explicar porque algumas crianças expostas a situações de risco são suscetíveis de manifestar problemas emocionais e comportamentais e outras não. Entretanto, apesar do potencial contido neste conceito, existem, ainda, muitas indagações e controvérsias acerca deste fenômeno que precisam ser revistas e discutidas de forma a contribuir para que se possam utilizar mais amplamente suas potencialidades no que se refere à promoção da saúde e instrumentalização dos profis- 
sionais que trabalham com indivíduos e grupos que vivem em situações de risco.

Em busca de um confronto com alguns desses questionamentos foi realizada a revisão de um conjunto de estudos que examinam a resiliência, utilizando como critério de inclusão aqueles produzidos pelos autores que, nos últimos quinze anos, mais têm publicado sobre o tema e, ao mesmo tempo, permitiam colocar em destaque as controvérsias. Este artigo aporta uma síntese desta revisão, focalizando, especificamente, as aproximações e as divergências entre as concepções de resiliência desses autores; o que tem sido estudado em termos de fatores de risco e de proteção associados ao conceito; e os problemas mais comumente identificados na construção do conhecimento nessa área.

\section{As concepções correntes de resiliência}

Rutter (1999) refere-se a resiliência como uma relativa "resistência" manifestada por algumas pessoas diante de situações consideradas potencialmente de risco psicossocial para seu funcionamento e desenvolvimento. Segundo o autor, justamente esse caráter relativo é que faz com que o fenômeno seja observado em algumas circunstâncias, mas em outras não, dependendo da etapa do ciclo vital na qual o sujeito se encontra quando enfrenta a adversidade e do domínio examinado no estudo. Pela mesma razão, fica excluída a possibilidade de se pensar a resiliência como um constructo universal aplicável a todas as áreas do funcionamento humano, pois se as circunstâncias mudam, a resposta da pessoa também pode ser modificada.

A resiliência, segundo Rutter (1987), seria resultante da interação entre fatores genéticos e ambientais, os quais, também, oscilam em sua função, podendo atuar como proteção em certos momentos e, em outros, como fator de risco. Assim, para compreender porque algumas pessoas se mostram resilientes apenas em determinadas situações é imprescindível examinar, primeiramente, essas interações, considerando-as a partir do contexto em que acontecem e do momento histórico vivido pela pessoa, já que ambos influenciam na forma como a adversidade é experienciada e, conseqüentemente, na resposta do sujeito aos problemas. Este autor ressalta, ainda, que esta 'capacidade' para superar as adversidades inclui desde a habilidade da pessoa para lidar com as mudanças que acontecem em sua vida, sua confiança na própria auto-eficácia, até o repertório de estratégias e habilidades de que dispõe para enfrentar os problemas com os quais se depara.

Com uma abordagem semelhante, Masten e Coatsworth (1995), Luthar, Cicchetti e Becker (2000) consideram que a resiliência se refere à obtenção de resultados desenvolvimentais esperados, apesar da presença de desafios significativos para o desenvolvimento e a adaptação do sujeito. Estes autores destacam duas condições críticas associadas ao conceito: A primeira refere-se à exposição da pessoa a uma ameaça significativa ou a uma severa adversidade; na segunda há concretização de uma adaptação efetiva, apesar da 'agressão’ em potencial que repercute no desenvolvimento do sujeito.

Para Zimmerman e Arunkumar (1994), o termo resiliência refere-se aos fatores e ao processo que interrompem uma trajetória de risco para transtornos de comportamento ou psicopatologias, resultando em respostas positivas mesmo na presença de adversidade. Aplicada à área da saúde mental, esta concepção pode ser compreendida como a capacidade de o sujeito evitar a reprodução, na vida adulta, dos conflitos e dos desajustes familiares, vividos na infância. Assim, por exemplo, mesmo que um dos pais tenha sido alcoolista, nem por isso o filho está condenado a desenvolver esse problema e tornar-se também um alcoolista na idade adulta, apesar dos altos índices de recorrência desta doença para a descendência, apontados na literatura.

Já Garmezy (1993) concebe a resiliência como a capacidade de recuperar o padrão de funcionamento após experienciar uma situação adversa, sem que, no entanto, deixe de ser atingido por ela. Esta concepção está associada à idéia de que a pessoa resiliente, vivendo sob uma situação de ameaça ao seu bem-estar, pode se curvar, perder suas forças e ainda se recuperar. A enfase nesta capacidade do sujeito para retomar os padrões de comportamento habituais que possuía antes de vivenciar a adversidade pressupõe que ela funcionava relativamente bem ao se deparar com a situação negativa e somente a partir deste momento passa a ter dificuldades, mas que algo se produz, levando-a a recuperar sua forma. Embora esta dimensão atribuída ao conceito de 
resiliência tenha sido explorada em muitas pesquisas, é importante destacar que sua aplicabilidade parece ser mais apropriada ao estudo de populações que, ao longo de sua vida, construíram um "padrão" de comportamento. Nesse sentido, pensar, por exemplo, em crianças que vivem as etapas iniciais de seu desenvolvimento, esta concepção mostra-se limitada visto que, nestes casos, é difícil falar de um "padrão” prévio de respostas que poderia ser retomado.

Dando ênfase à idéia de processo, Cyrulnik (2001) considera que resiliência traduz um conjunto de fenômenos articulados entre si, que se desenrolam, ao longo da vida, em contexto afetivo, social e cultural, podendo ser metaforicamente comparado à arte de navegar em meio à tempestade. É, pois, uma história que se constrói, quotidianamente, desde o início da vida, a cada ação, a cada palavra, num longo processo que se inscreve em um contexto específico e se reconstrói de forma coletiva, ao longo do tempo, na qual o ambiente e tudo que o compõe são co-autores. A realidade em que o sujeito vive pode ser ameaçadora, colocando em risco a qualidade de seu viver e fazendo-o sofrer, mas ele consegue encontrar recursos que o ajudam a avançar e prosseguir. Para este autor, a resiliência se refere muito mais à evolução e à história de um sujeito, do que a ele mesmo. É, portanto, o caminho construído que é resiliente.

Por outro lado, os autores que utilizam o conceito família resiliente partilham da idéia de que esta característica se constrói numa rede de relações e de experiências vividas ao longo do ciclo vital e através das gerações, capacitando a família para reagir, de forma positiva, às situações potencialmente provocadoras de crises, superando essas dificuldades e promovendo sua adaptação de maneira produtiva a seu próprio bem estar. De modo geral, esses autores ressaltam que este conceito tem como foco a família como um todo em vez de se restringir ao indivíduo dentro da família. Ao mesmo tempo, referem que muitos aspectos estudados na resiliência individual têm sido incorporados à noção de família resiliente, tais como: a ênfase em um processo desenvolvimental e não em um fenômeno estático, a importância do momento em que o sujeito e a família se encontram quando se deparam com a adversidade (Hawley \& DeHann,1996; Walsh, 1998).
Para Walsh (1996; 1998), o conceito "família resiliente" diz respeito ao processo interacional que se desenrola nela enquanto unidade funcional, ao longo do tempo, fortalecendo a ambos (indivíduo e conjunto). Trata-se de um processo mediante o qual a família enfrenta seus períodos de crise ou desorganização; resiste às privações prolongadas e efetivamente se reorganiza. Já Hawley e DeHann (1996) dizem que este conceito descreve a trajetória que uma família percorre no sentido de sua adaptação e prosperidade, quando enfrenta uma adversidade, tanto no momento em que vivencia essa situação quanto ao longo do tempo. De acordo com essas autoras, tratase de um processo desenvolvimental único que inclui padrões de organização, de comunicação, de recursos pessoais e comunitários para a solução de problemas, possibilitando à família criar sua própria trajetória, crescer e prosperar, ao mesmo tempo em que responde à situação adversa. Por outro lado, para McCubbin e McCubbin (1993), que examinam o sistema familiar no enfrentamento tanto de circunstâncias normativas como não normativas, as "famílias resilientes” têm um padrão estabelecido de vínculos e flexibilidade, sendo mais capazes de administrar privações e mobilizar forças que resultam em respostas positivas diante de situações provocadoras de crise. Essas famílias são capazes de se preservar como unidades funcionantes e desempenhar suas tarefas durante a crise.

Ainda, em relação às concepções de resiliência é pertinente registrar sua aplicação ao conjunto da coletividade; segundo Mangham, McGrath, Reid e Stewart (2002) esta é uma tarefa mais abstrata, reservada para aqueles grupos/comunidades que enfrentam crises ou eventos desfavoráveis de maneira a contribuir para sua consolidação, melhoria de seus recursos, tendo uma atitude no sentido de se adaptar.

Embora as concepções correntes de resiliência façam referência ao indivíduo, à família e outros grupos, é importante destacar que a maioria dos estudos produzidos nos últimos anos, mesmo que falem das influências do contexto familiar, a focalizam, predominantemente, no âmbito individual. São trabalhos desenvolvidos, geralmente, sob a perspectiva da psicopatologia e aportam uma significativa base de conhecimentos acerca dos fatores de risco e de proteção, envolvidos neste processo, e das característi- 
cas das pessoas nas quais este fenômeno é observado. Por outro lado, os estudos que examinam a resiliência como característica do grupo familiar são desenvolvidos geralmente com uma orientação sistêmica e introduzem o exame de fatores específicos relacionados às famílias e não apenas aos indivíduos, como a estabilidade e a coesão entre seus membros. Já o estudo da resiliência atribuída à certas coletividades aporta conhecimento substancial acerca das características grupais e dos fatores de risco e de proteção em sua interface coletiva como, por exemplo, o suporte social mútuo e o nível de participação de seus membros.

Assim, em síntese, as concepções de resiliência examinadas nesta revisão podem ser classificadas em uma das três categorias já referidas por Werner (1995), ou seja: a) a capacidade do ser humano (indivíduo; família ou comunidade) de manifestar resultados desenvolvimentais esperados, apesar dos riscos presentes no ambiente, os quais podem comprometer esse processo; b) a manutenção de certas competências, mesmo na vigência de adversidades; c) a capacidade do ser humano de recuperar-se das adversidades que experiencia ao longo de sua trajetória vital. Cada uma destas categorias aporta limites e possibilidades, devendo, portanto, ser cuidadosamente examinadas quanto a sua aplicabilidade, tanto na prática profissional quanto na pesquisa.

Outro aspecto importante a destacar é que o conceito de resiliência pressupõe a presença de circunstâncias de vida adversas quando, então, o ser humano é confrontado com os desafios que se inscrevem em seu interior, os quais colocam à prova sua capacidade de enfrentá-los. Nesse sentido, exprime um paradoxo, uma vez que é, justamente, na vigência de situações adversas que o ser humano revela potencialidades extraordinárias. Quando olhada sob este ponto de vista, resiliência traduz uma dimensão de positividade inserida nas reações dos sujeitos frente aos desafios que, inegavelmente, aporta uma perspectiva promissora em termos da saúde e do desenvolvimento humano, principalmente, junto às populações que vivem em condições psicossociais desfavoráveis.

\section{Fatores de risco e de proteção associados ao estu- do da resiliência}

A presença de uma condição adversa (ou de risco) está, sem dúvida, atrelada ao conceito de resiliência. Masten e Coatsworth (1995) dizem que este termo deve ser usado somente para aqueles casos em que a pessoa responde positivamente em presença de risco significativo, devendo ser evitado quando a resposta é positiva, mas não houve essa exposição. Diferente da idéia de invulnerabilidade, resiliência diz respeito a uma capacidade de enfrentar e responder bem quando há perigo e possíveis conseqüências negativas, ou seja, não se está diante de uma situação em que a pessoa não experimente o estresse, ou que não se sinta atingida pela sua adversidade, nem tampouco que o risco tenha sido afastado. Pelo contrário, de acordo com Cyrulnik (2001), o sujeito resiliente conserva as marcas do que enfrentou. Elas estão presentes em suas lembranças, em seus sentimentos. Sua história permanece em sua memória, mas a pessoa é capaz de se recuperar porque encontra o suporte que a ajuda a prosseguir e delinear uma trajetória de vida que, do ponto de vista social e cultural, pode ser considerada positiva.

A literatura mostra que a resiliência tem sido examinada junto a populações expostas a adversidades de natureza diversa como a guerra (Davis, 2000; Sigal, 1998; Valent, 1998); a pobreza extrema (Garmezy, 1991; 1993); a convivência com a doença mental (Rutter, 1994), os maus tratos (Kolbo, 1996), a prematuridade do bebê, as restrições nutricionais, as longas rupturas com as pessoas significativas, as limitações físicas e mentais, a institucionalização prolongada, entre outros (Rutter, 1995; Vinay, Esparbés-Pistre \& Trap, 2000).

Especialmente importante é a presença concomitante de diversas condições de risco, num mesmo contexto, constituindo o que Garmezy (1993) chama de "cadeia de risco". Os estudos de Rutter (1994), sobretudo aquele em que ele toma por base crianças inglesas, com idade em torno de dez anos, vivendo em condições de pobreza, mostraram que os transtornos psiquiátricos estavam relacionados com a presença simultânea de problemas crônicos como a discórdia entre os pais, o baixo status sócio econômico, a história de criminalidade nos pais, a 
existência de doença mental no principal cuidador da criança e o fato de elas pertencerem a uma família numerosa.

Esses autores referem que a presença acumulada de estressores, num mesmo contexto, pode explicar até 33\% dos índices de transtornos psiquiátricos em crianças expostas a múltiplos riscos (Garmezy, 1993). Entretanto, mesmo que este índice seja elevado, é importante destacar que, ainda, resta um percentual muito maior, dentro do qual é possível que algumas crianças encontrem as condições que lhes possibilitem delinear uma trajetória de vida positiva, mesmo estando expostas a múltiplos riscos.

A pobreza crônica, segundo Garmezy (1993), favorece o acúmulo de estressores que, muitas vezes, persistem ao longo dos anos, produzindo uma cadeia de riscos cujos efeitos são capazes de reduzir e/ou destruir as possibilidades de resposta positiva da criança pobre às adversidades cotidianas que vivencia, colocando-a, cada vez mais, em desvantagem. Esta cadeia geralmente começa com a inadequada nutrição e supervisão médica para a mãe durante a gravidez, segue com a desnutrição e as doenças ligadas à inacessibilidade de cuidados de saúde adequados; as dificuldades e limitações na fase de escolarização e pode culminar com o desemprego crônico, ou mesmo o sub-emprego com salários insuficientes, na idade adulta.

Por outro lado, mesmo que a resiliência esteja atrelada à presença de uma condição adversa para ser reconhecida como tal, não podemos esquecer que no contexto onde os sujeitos se desenvolvem outros elementos estão presentes. Vinay e cols (2000) dizem que falar de resiliência implica em falar não apenas dos riscos impostos pelas circunstâncias vividas pelo sujeito, mas, também, em reconhecer a presença, neste mesmo ambiente, de certos fatores que podem proteger o ser humano, atenuando ou neutralizando os efeitos negativos dos riscos e viabilizando a construção da resiliência.

Dentre os fatores de proteção Cyrulnik (2001) aponta o temperamento da criança - flexível, confiante e capaz de buscar ajuda exterior -; o contexto afetivo no interior do qual a criança vive seus primeiros anos - um clima familiar que aporte a segurança necessária para que desenvolva a confi- ança em si mesma e nos outros. Segundo o autor, esses fatores têm um caráter complementar, uma vez que, isoladamente, eles não garantem uma evolução resiliente. Uma criança que vive em condições de risco, mesmo tendo um temperamento que favoreça as interações com outras pessoas e o ambiente, poderá seguir uma evolução resiliente em uma família ou em uma sociedade, mas em outra não.

Outros fatores de proteção incluem: os cuidados responsáveis e constantes dirigidos à criança; as expectativas positivas nela depositadas; as relações de apego seguro; a coesão entre os membros da família, a existência de pelo menos um adulto verdadeiramente interessado na criança, capaz de bem cuidá-la e protegê-la, mesmo na ausência de responsabilidade dos pais, assim como a sensibilidade materna que, juntamente com o suporte social são, segundo Silva (2003), capazes de reduzir substancialmente os problemas emocionais e comportamentais, principalmente para crianças que crescem em ambientes com maiores desvantagens.

De modo geral, pode-se afirmar que o estudo da resiliência tem focalizado desde os eventos adversos estudados de forma isolada, até a associação de múltiplos riscos, alguns sendo examinados em um período de tempo delimitado e outros de forma longitudinal, cobrindo uma seqüência temporal mais extensa. Alguns estudos tratam, por exemplo, de uma situação adversa que está sempre presente na vida dos seres humanos e outros levam em conta adversidades que acontecem em um momento específico do ciclo vital, podendo, após, o sujeito ou a família, retomar seu modo de funcionamento anterior. É importante assinalar que, embora as pesquisas desenvolvidas em diferentes contextos de observação aportem múltiplas possibilidades de olhar o mesmo fenômeno e, de certo modo, garantam a expansão do conhecimento, existem diferenças significativas entre elas que não podem ser ignoradas, já que determinam os rumos de uma investigação e, conseqüentemente, seus resultados.

Quando McCubbin e McCubbin (1993) examinam o sistema familiar vivenciando a doença de um de seus membros e retomando a unidade familiar após a experiência, estão falando da resiliência que se manifesta em um contexto específico, mas, não, necessariamente, dos mesmos fatores e meca- 
nismos que podem entrar em ação quando se trata de seres humanos vivenciando outras adversidades como a guerra ou a pobreza extrema. Da mesma forma, quando uma pesquisa envolve sujeitos que já nasceram em condições adversas, é importante não perder de vista que, para eles, as adversidades não promovem alteração em seu estilo de vida, visto que são partes constituintes de seu contexto. Nestes casos, parece mais apropriado direcionar os estudos no sentido de investigar, por exemplo, o que essas pessoas podem encontrar nestes contextos que vão permitir que seu desenvolvimento siga em uma direção positiva ou não.

\section{Problemas associados com a construção do conhe- cimento acerca da resiliência}

Embora a resiliência seja um conceito que comporta expectativas promissoras em termos de prevenção e promoção da saúde, é importante não considerá-lo como a única resposta para os possíveis problemas decorrentes da exposição dos seres humanos às adversidades; ele é ainda relativamente recente e permeado de muitos vazios e incertezas. Há que levar em conta as questões conceituais e operacionais que, embora não sejam suficientes para comprometer seu potencial, devem ser consideradas como sinais de alerta.

Do ponto de vista conceitual, pelo menos duas dicotomias são identificadas.

A primeira considera a resiliência ora como um resultado desenvolvimental positivo que emerge em circunstâncias adversas (Garmezy, 1993; Masten \& Coatsworth, 1995), ora como uma trajetória desenvolvimental positiva (Cyrulnik, 2001; Zimmerman \& Arunkumar, 1994). Embora esta dualidade não chegue a caracterizar uma contradição, visto que emergem resultados a cada etapa do desenvolvimento que se estruturam sobre outros já manifestados antes, colocando o desenvolvimento humano como uma seqüência histórica de resultados transitórios, ela deve ser examinada com cuidado, especialmente porque anuncia a existência de diferentes posições teóricas que podem repercutir sobre a prática profissional, uma vez que conceber a resiliência como uma trajetória construída ao longo do ciclo vital comporta a idéia de que o investimen- to, no sentido de promover essa construção, pode acontecer em qualquer momento, desde a infância até a velhice.

A segunda dicotomia considera a resiliência ora como «a capacidade de algumas pessoas enfrentarem adversidades acumuladas e situações estressantes, sem prejuízo para seu desenvolvimento», de acordo com o que dizem Vicente e Valentini (1996) apoiadas nos trabalhos de Rutter, ora como a capacidade do sujeito para enfrentar as adversidades e prosseguir apesar do impacto que estas exerceram sobre sua vida (Cyrulnik, 2001; Zimmerman \& Arunkumar, 1994). Aqui se vê contradição, pois pensar que adversidades como a guerra e os maus tratos na infância possam não provocar prejuízo para o desenvolvimento de uma pessoa é, de certa forma, negar sua sensibilidade. Esta posição aproxima-se do conceito de invulnerabilidade que, durante certo tempo, foi equivocadamente utilizado como sinônimo de resiliência; e os estudos qualitativos com sujeitos que viveram as atrocidades da guerra destacam o impacto negativo dessa experiência, mostrando que as pessoas não são invulneráveis. Como diz Cyrulnik (2001), elas conservam as lembranças das humilhações, perdas, vergonha e dos sentimentos de ódio e, muito tempo depois ainda sofrem os prejuízos desta vivência. O que as diferencia é terem conseguido se recuperar e construir uma forma de viver que lhes permite responder às demandas quotidianas, apesar dos prejuízos que computam.

Do ponto de vista operacional, os problemas envolvidos com o estudo da resiliência incluem a seleção de indicadores para mensurar este fenômeno multideterminado, assim como sua relatividade (manifestação em apenas algumas áreas do funcionamento) e instabilidade (presença em alguns pontos da trajetória vital de um ser humano, mas, em outros não).

A seleção dos indicadores de resiliência representa uma das etapas mais cruciais do processo de pesquisa. Dependendo dos recursos técnicos, humanos e da abordagem do estudo, este conceito pode ser examinado ou através de respostas consideradas positivas em termos de desenvolvimento e das expectativas sociais que vigoram para o contexto no qual ele se realiza, ou ainda, através da presença (ou ausência) de problemas de ordem emocional, 
comportamental, que podem se manifestar quando a pessoa está exposta a um contexto adverso.

As duas possibilidades exigem atenção cuidadosa, pois ambas têm limitações. A primeira, porque está relacionada com a determinação do que seja uma resposta positiva, uma vez que esta, geralmente, está ligada ao significado que os sujeitos atribuem à experiência que estão vivenciando e ao padrão de normatividade considerado para aquela população específica que está em estudo, no contexto onde vivem. Nesta intersecção é que se debate a questão da subjetividade em relação ao que está sendo considerado como adversidade e, também, ao que seja uma resposta positiva, do ponto de vista das pessoas que vivem a experiência que o pesquisador está tentando compreender. Com relação a essa questão específica, Luthar e cols (2000) e Laurencelle (2000) chamam atenção tanto para a variabilidade associada ao estudo dos fenômenos nas ciências humanas quanto para a subjetividade imbricada nas pesquisas desenvolvidas nas ciências em geral. Nesse sentido, a definição dos indicadores de resiliência estará sempre sujeita aos mesmos limites e possibilidades contidos em qualquer outro tipo de pesquisa que envolva comportamentos humanos.

Por outro lado, é importante levar em conta que, segundo Rutter (1999), a resiliência é, caracteristicamente, um fenômeno relativo o que contribui para dificultar sua operacionalização. Possivelmente sua natureza multidimensional propicia que a resiliência se manifeste em algumas circunstâncias e noutras não, ou que se mostre de diferentes maneiras, de acordo com os domínios que estão sendo considerados. Entretanto, mesmo que esta característica tenha gerado questionamentos no sentido de esclarecer se os estudos que mostram essas diferenças estão tratando do mesmo constructo, Luthar e cols (2000) referem que, geralmente, espera-se uma certa concordância entre os estudos desenvolvidos em domínios de ajustamento teoricamente similares, mas, não necessariamente, entre aqueles que são conceptualmente distintos. Dessa forma, se uma criança mostra-se resiliente sob o ponto de vista acadêmico-cognitivo, ela, provavelmente, responderá positivamente na esfera do comportamento acadêmico, também, mais tarde.

Estes mesmos autores referem que muitas das pessoas que se sobressaem em alguns domínios, geralmente, continuam manifestando um perfil de adaptação positiva, ao longo do tempo. O estudo longitudinal, desenvolvido por Werner (1995), mostrou que a maioria das crianças consideradas como resilientes mantiveram um adequado nível de funcionamento na vida diária. De forma enfática, Luthar e cols (2000) sugerem que no âmbito da pesquisa deve ser especificado com clareza as condições e o domínio no qual a investigação está sendo conduzida, de tal modo que fique claro onde e de que maneira seus resultados podem ser aplicados.

Da mesma forma, a instabilidade do fenômeno resiliência, ao longo do ciclo vital, constitui-se em um desafio sempre presente no processo de pesquisa. Não há dúvidas de que tanto as pessoas resilientes como as não resilientes mostram flutuação em sua maneira de enfrentar e responder às adversidades, em diferentes etapas de sua vida e, sendo assim, seria ilusório esperar um padrão estável e unificado de respostas. Principalmente nos dias de hoje em que, cada vez mais, ressurge o caráter provisório da natureza do sujeito que não mais é visto como uma identidade fixa, essencial ou permanente. Sujeito este que se transforma continuamente a partir de suas interações e que, por esta razão, não poderia ter a mesma resposta diante de todas as situações que vivencia, ao longo de sua vida. De acordo com Hall (2000), é importante considerar que o sujeito assume diferentes identidades em diferentes momentos de sua vida e que nem sempre estas identidades são coerentes e convergentes, mas são capazes de o impulsionar em diferentes direções, criando um repertório diverso de possíveis respostas às várias situações. Sendo assim, a instabilidade do fenômeno resiliência coloca em destaque justamente uma das características mais genuínas do ser humano, isto é, a sua capacidade de se reconstruir, ao longo de sua vida, de se renovar a cada nova experiência, sem, contudo, deixar de ser o que era anteriormente.

Muitos outros problemas estão associados com a construção de conhecimento acerca da resiliência, os quais não foram apontados neste artigo. De qualquer forma, as questões enumeradas são suficientes para anunciar que tanto a conceitualização quanto a operacionalização da resiliência têm sido um desafio com o qual os pesquisadores, inevitavelmente, se 
deparam em algum momento do seu trabalho. Anunciam, também, que a delimitação de um problema específico a ser pesquisado dentro desta temática deve ser feita a partir de uma decisão conceitual e metodológica, uma vez que se trata de um fenômeno multideterminado que necessita de instrumentos apropriados de acordo com o contexto onde o estudo se desenvolve e com a população focalizada.

\section{Conclusão}

Apesar desses problemas apontados, a relevância do conceito de resiliência para a saúde e o desenvolvimento humano não diminui. Especialmente do ponto de vista da prática, resiliência representa um dos caminhos possíveis para que os profissionais da saúde possam trabalhar, de forma prioritária com a saúde, dando ênfase às potencialidades dos seres humanos. Nesse sentido, representa uma "possibilidade técnica” para o exercício de uma assistência ética em saúde, já que a incorporação deste conceito, pelos profissionais, pressupõe a desconstrução de algumas crenças, de alguns conceitos e, principalmente, a desconstrução da desesperança atrelada à dimensão de negatividade do processo saúde-doença que, ainda hoje, dá sustentação às práticas profissionais em alguns setores da área da saúde. Representa, ainda, uma possibilidade de reencaminhar a insatisfação decorrente do conformismo e aceitação de que as pessoas que nascem em ambientes onde a doença, a violência, a dependência química e outros problemas se inscrevem, estão condenadas a apresentarem algum tipo de transtorno na vida adulta. Falar de resiliência é, portanto, falar da possibilidade de quebra de previsões e de expectativas de continuidade dos problemas.

Do ponto de vista social, o conceito de resiliência comporta uma nova possibilidade de se trabalhar com os problemas experimentados pelo grande contingente de população que, cada vez mais, está vivendo em condições adversas, exposto a um potencial de risco significativo, principalmente, para as crianças que crescem nestes ambientes. Baseado em dados estatísticos da OMS, Cyrulnik (2001), chama atenção que uma em cada duas pessoas foi ou será gravemente atingida por alguma forma de trauma ao longo de sua vida, seja este na forma de guer- ra, violência urbana, negligência, abuso físico e sexual e muitos outros.

Entretanto, mesmo detendo um potencial valioso em termos de prevenção e de promoção da saúde, o conceito de resiliência não deve ser usado de forma ingênua, depositando, sobre as famílias, a responsabilidade para resolver problemas cuja solução, muitas vezes, extrapola seus limites de competência. Embora seja, justamente, no contexto de ameaça globalizada que assola o mundo contemporâneo que se abre espaço para o estudo da resiliência de forma mais intensificada, não podemos esquecer que é, também, nesta intersecção que esbarram as dimensões éticas e políticas da resiliência, visto que esta, habitualmente, se manifesta no interior de macro adversidades sobre as quais as famílias dificilmente detêm o controle. Adversidades estas que nem sempre lhes possibilitam manter interações positivas entre seus membros ou utilizar adequadamente os recursos que poderiam proporcionar condições de vida satisfatórias. Enfim, que dificultam o acesso das famílias aos recursos básicos para a sua sobrevivência e para que o desenvolvimento de seus membros possa seguir um curso normativo. De qualquer modo, apesar do potencial contido no conceito de resiliência, este não deve ser usado para isentar da responsabilidade aqueles que deveriam trabalhar para gerar as condições básicas necessárias a um viver saudável.

\section{Referências Bibliográficas}

Cyrulnik, B. (2001). Les vilains petits canards. Paris: Odile Jacob.

Davis, R.E. (2000). Refugee experiences and Southeast Asian women's mental health. Western Journal of Nursing Research. 22(2), 144-168.

Garmezy, N. (1991). Resiliency and vulnerability to adverse developmental outcomes associated with poverty. American Behavioral Scientist. 34(4), 416-430.

Garmezy, N. (1993). Children in poverty: resilience despite risk. Psychiatry 56, 127-136.

Hall (2000). A identidade cultural na pósmodernidade. (T.T. Silva \& G.L. Louro, Trad.) Rio de Janeiro: DP\&A. 
Hawley, D.R. \& DeHann, L. (1996). Toward a definition of family resilience: integrating lifespan and family perspectives. Family Process, 35(3), 283-298.

Kolbo, JR. (1996). Risk and resilience among children exposed to family violence. Violence and victims, 11(2).

Laurencelle, L. (2000). Les analyses statistiques. Em S. Bouchard \& C. Cyr, (Orgs.), Recherche psychosociale - pour harmoniser recherche et pratique. Québec: Université du Québec.

Luthar, S.S., Cicchetti, D. \& Becker, B. (2000). The construct of resilience : a critical evaluation and guidelines for future work. Child Development, 71(3), 543-562.

Mangham, C., McGrath, P., Reid, G. \& Stewart, M. (2002). Resiliency: relevance to health promotion. http://.hc-sc.gc.ca/hppb/alcoholotherdrugs/pube/resilncy/analysis.htm. Acessado em 01 de Julho de 2001.

Masten, A. \& Coatsworth, J.D. (1995). Competence, resilience, and psychopathology. Em D. Ciccetti \& D. J. Cohen (Orgs.), Developmental psychopatology-risk, disorder, and adaptation. New York: John Wiley \& Sons.

McCubbin, M.A. \& McCubbin, H.I. (1993). Families coping with illness: the resilience model of families stress, adjustment, and adaptation. Em C. Danielson; B. Hamel-Bissell \& Winstead-Fry (Orgs.), Families, health, \& illness perspectives on coping and intervention (pp. 2163). St Louis: Mosby.

Rutter, M. (1987). Psychosocial resilience and protective mechanisms. American Journal of Orthopsychiatry, 57(3), 316-331.

Rutter, M. (1994). Individual Characteristics as a Force in Development . Em M.Rutter \& D. Hay Development through life (pp.79-111). London: Blackwell Science

Rutter, M. (1995). Resilience: some conceptual considerations. Journal of Adolescent Health, New York, 14, 626-631.
Rutter, M. (1999). Resilience concepts and findings: implications for family therapy. Journal of Family Therapy, 21, 119-144.

Sigal, J.J. (1998). Long-term effects of the holocaust: empirical evidence for resilience in the first, second, and third generation. Psychoanalytic Review, 85(4).

Silva, M.R.S. (2003). A construção de uma trajetória resiliente durante as primeiras etapas do desenvolvimento da criança: o papel da sensibilidade materna e do suporte social. Tese de Doutorado, Universidade Federal de Santa Catarina, Florianópolis.

Valent, P. (1998). Resilience in child survivors of the holocaust: toward the concept of resilience. Psychoanalytic Review, 85(4).

Vicente, C.M. \& Valentini, W. (1996). A reabilitação psicossocial em Campinas. Em A. Pitta (Org.), Reabilitação psicossocial no Brasil (p p. 48-53). São Paulo: Hucitec.

Vinay, A., Esparbés-Pistre \& Trap, P. (2000). Attachement et stratégies de coping chez l'individu résilient. La Revue Internationale de l'éducation familiale, 9-29.

Zimmerman, M.A. \& Arunkumar, R. (1994). Resiliency research: implications for schools and policy. Social Policy Report, 8(4), 1-17.

Walsh, F. (1996). The concept of family resilience: crisis and challenge. Family Process, 35(3).

Walsh, F. (1998). Strengthening family resilience. New York: The Guilford.

Werner, E.E. (1995). Resilience in development. Current Directions in Psychological Science, 4 (3), 81-85. 